\title{
Effects of Computer/Laptop Screen Radiation on Human Beings
}

\author{
Vijay Kumar, Deepak Kotnala, J. S. Kalra, Bhaskar Pant
}

\begin{abstract}
In offices, many people work continuously in front of the screen of computer and laptop. Screen of such type of equipments continuously produce a radiations. These radiations are incident on the face of workers. It affect to the eye and other organs of the body. The radiations enter inside the body and electromagnetic energy is absorbed by the cells and tissues. In this manuscript, it is observed that the radiation of screen of computer/laptop may be harmful for the human beings after a long exposure. It is suggested that people should work for a short duration and if is mandatory to work for a long time in front of screen, the duration of working may be divided into parts.
\end{abstract}

Key Words: Computer/laptop screen, Electromagnetic radiation, Health effects,

\section{INTRODUCTION}

Electromagnetic waves are emitted by man-made and natural sources and they play important role in our life. Electromagnetic (EM) waves consist of both electric and magnetic field components which are mutually perpendicular to the direction of propagation of the waves. These waves include radio wave, infrared radiation, visible light, ultraviolet radiation, X-ray and Gamma rays. These EM waves are everywhere so human beings are always exposed to these radiations. Long exposure of the radiation may be responsible to the risk of cardiovascular disease and other health problems [1]. Electromagnetic radiation indirectly affect on muscles and nerve cells of the body. Many health related problems such as headache, cardiac disease, burning sensation, redness, fatigue are observed due to long time exposure of radiation. The radiation emitted by laptops, computer and computer components radiate extremely low frequency (ELF) EM radiation. These same kind of radiation are emitted from television sets , electrical power lines, and other electronic appliances. Intensity of the radiation coming from the computer and laptops is less but as user is much closer, it will produce health problems. Radiation in which user exposed to this radiation are radio waves, ultraviolet light and visible and extremely low frequency [2]. Computer visual Display Unit (VDU) are categorized into two types that is cathode ray tube (CRT) and Liquid crystal display (LCD). CRT is vacuum based tube in which beam of electron is projected on phosphorescent screen to view image. CRT used to form image like in computer screen and oscilloscope etc.

Revised Manuscript Received on October 20, 2019.

Vijay Kumar, Professor, Department of Physics, Graphic Era Hill University, Dehradun, India

Email: vijay_phd05@rediffmail.com

Deepak Kotnala, Student BSc, Department of Physics, Graphic Era Hill University, Dehradun, India

J. S. Kalra, A. P. Department of Mechanical Engineering, Graphic Era Hill University, Dehradun, India.

Bhaskar Pant, Professor, Department of Computer Science and Engineering, Graphic Era Hill University, Dehradun, India.
LCD is modern based technology that uses modulating of liquid crystal combine with polarizer which is used in computer screen. Radiation from such kind of devices (VDUs) causes strain and dryness in eyes and irritation. These radiations (ELF) can cause various health hazard like difficulty in sleep and allergy also can cause cancer cardiac problem and Alzheimer diseases [3]. As we know CRT is used to detection of growth of fetus in pregnant woman long use of CRT could cause High rates of abnormal birth and miscarriages. In EM waves, magnetic components are more penetrated than electric components in human being also radiation decay rapidly as the distance is increased from the source $[3,4]$.

\section{REVIEW OF LITERATURE}

In daily life, the equipments we are using produce electromagnetic radiations continuously and we are living under the blanket of electromagnetic fields. Most of the negative impacts are especially in the spectrum of Radiofrequency (RF) band which is used in wireless communications. Alongside the across the board utilization of mechanical items in everyday life, the natural impacts of electromagnetic waves have started to be all the more broadly examined. Advantages of EM waves are countless but as we know anything have both advantage and disadvantage. Many researchers observe about the harmful effects of electromagnetic fields generated from various sources. It can cause various types of cancer and disorders in human internal organs like brain, kidney, lungs etc [5,6].

\section{EFFECTS OF RADIATIONS}

Advantages of EM waves are countless but as we know anything have both advantages and disadvantages. Many researchers show on their research that the electromagnetic field generated from their source affect the human body cells and tissues. Long time exposure of radiation affect the living beings and some researchers suggest that it can cause various types of cancer and disorders in human internal organs like brain, kidney, lungs and many more. It is really a good matter on which we should talk about otherwise we may loss a whole generation but side effect of this good habit is in the form of health. Some paper research suggests that they are agreeing with the fact that the electromagnetic waves really effecting physically human body and also effecting human mentally. If we talk about mobile phones, they now becoming tool to get relaxation in doing work .

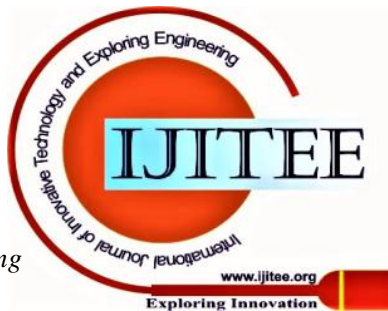




\section{Effects of Computer/Laptop Screen Radiation on Human Beings}

The average time which most of the people giving from the Static fields, when a charge is accumulated or present in the surface of material produces its electric field but when there is a physical movement of the charge it also produces a magnetic field. The external electromagnetic field may force the charge to do motion and when this charge moves it creates some potential difference. And that potential difference is so less $(<2000$ volts $)$ that the human body cannot feel. Generally, frequencies of these types of fields are almost $0 \mathrm{HZ}$. SOURCES- Industrial electrolysis, video displays, MRI and other scientific instrumentation, welding devices, etc. 3.3 Extremely Low Frequency(ELF)Extremely low frequency describes the frequency of less than $300 \mathrm{HZ}$. This type of field is almost useful to humans. In this range, electric power is also supplying throughout the word $(50 \mathrm{~Hz}-60 \mathrm{~Hz})[10,11]$. domestic appliances, electric engines in cars, busses, trains, etc. Possible

Health Effects- The positive part of technologic advancement makes the existence simpler, it might likewise include segments that disable the personal satisfaction using its specific adverse impacts. Electromagnetic waves can be created by numerous methods by humans also. Coming about because of the mechanical developments, the utilization of electromagnetic fields step by step increments, and in this way individuals are presented to these EM waves at higher extent. Especially, drastically expanding the cell phone client's numbers raises critical worries because of its latent capacity harm on individuals uncovered by RF waves. The general feeling is that there is no immediate proof of risky consequences for humans when brought near to low radiofrequency waves. A few examinations uncovered that various elements of EM fields did not demonstrated the deoxyribonucleic acid harm on various cells $[7,8]$.

\section{RADIATION IMPACT ON HUMANS}

In a cross sectional case control study directed to contemplate hereditary harm in people living in region of portable base stations, it was discovered that power thickness in the region inside $300 \mathrm{~m}$ from the base station surpassed as far as possible and was altogether higher contrasted with the region from where control tests were gathered. Hereditary harm parameters of DNA movement length, harm recurrence (DF) and harm file were fundamentally raised in the example bunch contrasted with utilization of microwave gadgets (cell phone, microwave) at residential level can have negative effect upon natural framework particularly on mind. The expanded responsive oxygen species (ROS) assume a significant job by upgrading the impact of microwave radiations which may cause neurodegenerative illnesses.[9,12] Aggravation of the sensory system prompts social changes and may fill in as an early pointer of unsettling influences in administrative elements of numerous frameworks. Introduction of the neural tissue to RFR can cause electrophysiological changes in the sensory system, for example, efflux of calcium particles from mind tissue. The non methodical and unexpected calcium efflux can show in numerous
SOURCES- Power lines, Domestic Distribution lines, particular qualities in sound controls. Normal and long haul

inconsistencies of neuronal control as calcium particle assumes a significant job in the elements of the sensory system, for example, the arrival of synapse. [13, 14]

In addition, RFR enacts endogenous narcotics in the mind, which thusly causes a decline in cholinergic movement prompting momentary memory shortfall. The pressure hormone "corticotrophin discharging factor" is likewise included. The occupants around versatile base station receiving wires essentially gripe or create cerebral pain, memory changes, tremors, unsteadiness, and burdensome manifestations and rest unsettling influence than controls. [15]

\section{RADIATION FROM DIFFERENT DISTANCES FROM VDUS}

ELF Radiation's Measurement's from Fronts of the Screen The result obtained for this present study confirmed the presence of ELF radiation's above background level to a minimum of distance of $50 \mathrm{~cm}$ from all the laptops and monitors studied at different locations of computer business centre's in Ondo state (IBook, Okitipupa and Ore). The radiation measured from the right and left sides of the laptops and monitors and almost same and seems insignificant due to the low values recorded and therefore not used in this present study.

\section{DISCUSSION}

Absolute mobile phone memberships added up to in excess of 6 billion out of 2013, relating to a worldwide entrance rate of $93.1 \%$ per 100 occupants. Considering over these grave insights one can undoubtedly infer that for all intents and purposes all aspects of biosphere is presented to constantly expanding RF radiations and in not so distant future electro contamination will inundate entire universe. Thus prudent steps ought to be created, close by ecological effect evaluations preceding establishment, and a sweeping restriction on establishment of telephone poles in secured normal territories and in places where imperilled species are available. The ELF radiation got from the screen of the workstations extended between $0.1-0.7 \mathrm{mG}$ for separations between $0-30 \mathrm{~cm}$. HPG had the most noteworthy ELF radiation level of $0.7 \mathrm{mG}$ at $0 \mathrm{~cm}$. Indeed, even at $40 \mathrm{~cm}$, HPG still had ELF radiation of $0.05 \mathrm{mG}$. HPE, HP2, HPC and HPM had the most reduced ELF radiation level of 0.1 $\mathrm{mG}$ at $0 \mathrm{~cm}$ and for all intents and purposes $0 \mathrm{mG}$ at $30 \mathrm{~cm}$. The ELF radiation acquired from the screen after the PC had been $\mathrm{ON}$ for 1 hour was a similar incentive as the one got at fire up. The ELF radiation got from the mouse cushion of the workstations went from as $0-5 \mathrm{mG}$ for separations between $0-30 \mathrm{~cm}$. ELF esteem estimated in the mouse cushion of the fourteen workstations utilized in the examination. It was found that HPE has the most minimal ELF estimation of $0.5 \mathrm{mG}$ at $5 \mathrm{~cm}$ away from the mouse cushion while AMP, HPG, HPD, AMA, HP1 and CPC have the most noteworthy ELF radiation estimation of $5 \mathrm{mG}$ each at $5 \mathrm{~cm}$ away from the mouse cushions.

Published By: 
Workstations, for example, ASU and HPE had the most reduced ELF radiation of $2 \mathrm{mG}$ at $0 \mathrm{~cm}[16,17]$.

It is accepted this is because of the nearness of the significant hardware and electrical parts legitimately under the mouse cushion. These parts make the PC work and simultaneously, they emit ELF radiation as warmth. Be that as it may, there is a continuous decrease in the ELF estimated as the Cell Sensor is moved away from the mouse cushion. The ELF radiation estimated following 1 hour is equivalent to $5 \mathrm{mG}$ at $0 \mathrm{~cm}$. The outcome acquired from the console is pretty much like be seen in the mouse cushion, the ELF radiation is moderately high. It is likewise found simply over the electrical and hardware parts of the PC are so to be expected to watch a comparable example in the radiation. It indicated the deliberate ELF from the console for various workstations. All the PCs under perception had ELF radiation of $5 \mathrm{mG}$ at $0 \mathrm{~cm}$. HPC and $\mathrm{HMN}$ had the most minimal ELF radiation from the console with an estimation of $0.4 \mathrm{mG}$ and $0.5 \mathrm{mG}$ at $5 \mathrm{~cm}$ separately, trailed by HP2 which has an estimation of $1.0 \mathrm{mG}$ at a similar good ways from the console. The ELF radiation estimated following 1 hour stayed at $>5 \mathrm{mG}$ at $0 \mathrm{~cm}$. It was likewise seen that HPC and HMN recorded the most minimal ELF are the two smaller than normal workstations (for example they are of littler size than customary workstations), this might be credited to the quantity of hardware segments under the console. The ELF radiation got from the devotee of the PCs HPE had the most noteworthy ELF radiation level of $5 \mathrm{mG}$ at $0 \mathrm{~cm}$. AMP and AMA had the most minimal ELF radiation level of $0.1 \mathrm{mG}$ at $0 \mathrm{~cm}$ and basically $0 \mathrm{mG}$ at 5 $\mathrm{cm}$. The ELF radiation got from the fan after the PC had been $\mathrm{ON}$ for 1 hour was a similar incentive as the one acquired at fire up $[18,19]$. There is no ELF radiation from the rear of the PCs, with the exception of the AMP which gave an ELF radiation estimation of $0.1 \mathrm{mG}$ at $0 \mathrm{~cm}$. All the PCs under perception had no distinguishable ELF radiation from the rear of the PC and the ELF radiation estimated at back of the PCs following 1 hour stayed $0 \mathrm{mG}$ in any event, for the AMP. The mean ELF radiation from the various pieces of the considerable number of workstations under perception at different separations is In this work, we have affirmed the nearness of ELF radiation over the foundation level, to a base separation of $50 \mathrm{~cm}$ from the PCs, screens, intuitive screen and CST Computer lab and ELF radiation diminishes with separation. The piece of a PC that the transmitted most elevated estimation of ELF radiation was the console while the rear of the PC had the least ELF radiation. It was uncovered from the investigation that the ELF radiation doesn't increment inside 1 hour of activity of the workstations. Looking at the got ELF esteems from radiations from a PC console proposes that small scale workstations discharge less ELF radiation than PCs of size extending from 14 inches -17 inches. The exploration thus suggested the utilization of the smaller than expected workstations among understudies and everybody in the general public. It further recommended the utilization of outside peripherals or remote console and mouse rather than direct utilization of the PC's console and mouse cushion. Likewise, government ought to examine the importation of went between $0.1-5 \mathrm{mG}$ at $0 \mathrm{~cm}$ as appeared in Table 2 .

PCs into the nation as PCs with low ELF just ought to be imported [20,21].

\section{CONCLUSION}

From the above analysis, it is concluded that people should keep away the monitor screen of TV, Computer and laptop during working on it. If working on computer screen become more, the radiation of the screen may penetrate inside the body and may affect the natural functioning of tissues and cells. The abnormal functioning of cells may responsible for many types of diseases. It is a natural process that when the cells become die, the new cells are generated. But due to the exposure of radiation of screen, the new cells are generated without die of old cell. It may be responsible for generation of tumour in the body. Similar types of abnormal activities are possible inside the body due to long exposure of radiation of computer/laptop screen.

\section{REFERENCES}

1. Vijay Kumar, R. P. Vats and P. P. Pathak, Harmful effects of 41 and $202 \mathrm{MHz}$ radiations on some body parts and tissues, Indian J. of Biochemistry and Biophysics, 45(4), 269-274, 2008

2. Vijay Kumar, R. P. Vats, S. Kumar and P. P. Pathak, Interaction of EMW with human body, Ind. J. Radio \& Space Physics, 37, 131-134, 2008.

3. Briggs, R. (1991). "Safety and health effects of visual display terminals". A chapter in GD Claytonand FE Clayton (eds), Patty's Industrial hygiene and toxicology, fourth edition, vol. 1,John Wiley \& Sons, Inc. FRN (2006). National Population Census Report, Federal Republic of Nigeria. web.archieve.org. Retrieved 15 October 2017.

4. Anisimov VN, Arutiunian AV, Burmistrov SO, Zabezhinskiı MA, Muratov EI, Oparina TI, Popovich IG, Prokopenko VM, Frolova EV. (1997). Effects of radiation from video display terminals of personal computers on free radical processes in rats. Biull Eksp Biol Med.; 124:192-4.

5. International Agency for Research on Cancer Non- Ionizing Radiation, Part 1: Static and extremely low-frequency (ELF) electric and magnetic fields. IARC Monographs on the Evaluation of carcinogenic Risks to Humans, (IARC, 2002), Volume 80, Lyon: IARC Press.

6. Anisimov VN, Arutiunian AV, Burmistrov SO, Zabezhinskiı̌ MA, Muratov EI, Oparina TI, Popovich IG, Prokopenko VM, Frolova EV. (1997). Effects of radiation from video display terminals of personal computers on free radical processes in rats. Biull Eksp Biol Med.; 124:192-4.

7. Briggs, R. (1991). "Safety and health effects of visual display terminals". A chapter in GD Claytonand FE Clayton (eds), Patty's Industrial hygiene and toxicology, fourth edition, vol 1,John Wiley \& Sons, Inc. FRN (2006). National Population Census Report, Federal Republic of Nigeria. web.archieve.org. Retrieved 15 October 2017.

8. IARC (2002). "Non-ionizing Radiation, Part 1: Static and extremely low-frequency (ELF) electricand magnetic fields". International Agency for Research on Cancer, Monographs onthe Evaluation of carcinogenic Risks to Humans: Volume 80. Lyon: IARC Press.

9. Mortazavi SM, Ahmadi J, Shariati M. (2007). Prevalence of subjective poor health symptoms associated with exposure to electromagnetic fields among university students. Bioelectromagnetics; 28:326-30.

10. 10. WHO (1986). "Provisional statements of WHO working group on occupational healthaspects inthe use of visual display units". World Health Organization. VDT News, vol.3(1):13.

11. M. R. Usikalu, T. T. Ikeh and C. O. Olawole (2014). Safe Distance to Extremely Low Frequency Radiation Associated with Power Transmission Lines Located in Ota, Southwest, Nigeria, International Journal of Engineering Technology, IJENS 14(2):118121 


\section{Effects of Computer/Laptop Screen Radiation on Human Beings}

12. International Agency for Research on Cancer Non- Ionizing Radiation, Part 1: Static and extremely low-frequency (ELF) electric and magnetic fields. IARC Monographs on the Evaluation of carcinogenic Risks to Humans, (IARC, 2002), Volume 80, Lyon: IARC Press

13. M. R. Usikalu, T. T. Ikeh and C. O. Olawole (2014). Safe Distance to Extremely Low Frequency Radiation Associated with Power Transmission Lines Located in Ota, Southwest, Nigeria, International Journal of Engineering Technology, IJENS 14(2):118121

14. 14. Radiation Protection Program Radiation from Computer Monitors. Retrieved from Environment, Health \& Safety: https://ehs.mit.edu/site/content/radiation-computer-monitors , (2010).

15. 15. M. L. Akinyemi, J. S. Kayode and M. R. Usikalu Investigation of Extremely Low Frequency (ELF) Hot Spots in the College of Science and Technology, Covenant University, Ota, Turkish Journal of Physics, (2011), 35(3): 359-361.

16. 16. International Agency for Research on Cancer Non- Ionizing Radiation, Part 1: Static and extremely low-frequency (ELF) electric and magnetic fields. IARC Monographs on the Evaluation of carcinogenic Risks to Humans, (IARC, 2002), Volume 80, Lyon: IARC Press

17. 17. Perez-Vega, C., Zamanillo, J. M., and Ipina, J. S. (2000). Assessment of Ionization Radiation from PC Monitors and TV Receivers. IEEE, 1048-1051. 14

18. 18. Radha, R., and Gurupranesh, P. (2014). Electromagnetic Radiation from Electronic Appliances. Journal of Mechanical and Civil Engineering, 41-46.

19. 19. Usikalu M. R and Akinyemi M. L (2012). Analysis of Radiation Dose around some Base Stations in Ota and Lagos Environ, International Journal of Basic and Applied Sciences, IJENS 12(5): 7-12.

20. 20. Usikalu M. R, Babarimisa I. O, Akinwumi S. A, Akinyemi M. L, Adagunodo T. A and Ayara W. A (2018) Radiation from Visual Display Unit, IOP Conference Series: Earth and Environmental Science, Volume 173 (1): 012- 039.

21. 21. Usikalu M. R. and Akinyemi M. L. (2007) Monitoring of radiofrequency radiation from selected mobile phones, Journal of Applied Sciences Research, 3(12): 1701-1704. 